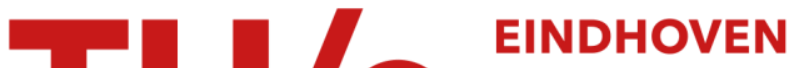

\section{Full color camouflage in a printable photonic blue-colored polymer}

Citation for published version (APA):

Moirangthem, M., \& Schenning, A. P. H. J. (2018). Full color camouflage in a printable photonic blue-colored polymer. ACS Applied Materials \& Interfaces, 10(4), 4168-4172. https://doi.org/10.1021/acsami.7b17892

\section{Document license:}

CC BY-NC-ND

DOI:

10.1021/acsami.7b17892

Document status and date:

Published: 31/01/2018

\section{Document Version:}

Publisher's PDF, also known as Version of Record (includes final page, issue and volume numbers)

\section{Please check the document version of this publication:}

- A submitted manuscript is the version of the article upon submission and before peer-review. There can be important differences between the submitted version and the official published version of record. People interested in the research are advised to contact the author for the final version of the publication, or visit the $\mathrm{DOI}$ to the publisher's website.

- The final author version and the galley proof are versions of the publication after peer review.

- The final published version features the final layout of the paper including the volume, issue and page numbers.

Link to publication

\section{General rights}

Copyright and moral rights for the publications made accessible in the public portal are retained by the authors and/or other copyright owners and it is a condition of accessing publications that users recognise and abide by the legal requirements associated with these rights.

- Users may download and print one copy of any publication from the public portal for the purpose of private study or research.

- You may not further distribute the material or use it for any profit-making activity or commercial gain

- You may freely distribute the URL identifying the publication in the public portal.

If the publication is distributed under the terms of Article 25fa of the Dutch Copyright Act, indicated by the "Taverne" license above, please follow below link for the End User Agreement:

www.tue.nl/taverne

Take down policy

If you believe that this document breaches copyright please contact us at:

openaccess@tue.nl

providing details and we will investigate your claim. 


\title{
Full Color Camouflage in a Printable Photonic Blue-Colored Polymer
}

\author{
Monali Moirangthem and Albertus P. H. J. Schenning*(i) \\ Functional Organic Materials \& Devices, Eindhoven University of Technology, P.O. Box 513, 5600 MB Eindhoven, The Netherlands
}

Supporting Information

ABSTRACT: A blue reflective photonic polymer coating which can be patterned in full color, from blue to red, by printing with an aqueous calcium nitrate solution has been fabricated. Color change in the cholesteric liquid-crystalline polymer network over the entire visible spectrum is obtained by the use of nonreactive mesogen. The pattern in the coating is hidden in the blue color dry state and appears upon exposure
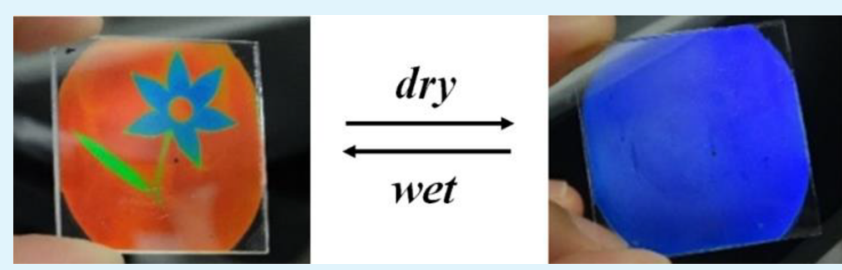
to water or by exhaling breath onto it due to different degrees of swelling of the polymer network. The degree of swelling depends on the printed amount of calcium which acts as a crosslinker. The printed full color pattern can also be hidden simply by using a circular polarizer. The responsive full color camouflage polymers are interesting for various applications ranging from responsive house and automobile decors to anticounterfeit labels and data encryption.

KEYWORDS: full color, responsive, cholesteric liquid crystals, photonic pattern, inkjet printing

\section{INTRODUCTION}

Adaptive structural colors that arise due to the presence of periodic alteration of refractive indices are abundantly found in nature $^{1}$ and perform various functions such as thermoregulation to control body temperature, signaling to communicate to other members of the same species, mimicry to warn predators, and camouflaging to hide from predators. ${ }^{2-4}$ Over the years, researchers have been working to generate adaptive full structural colors and camouflage in polymers. Such responsive photonic materials could be of interest in adaptive and camouflage textiles, smart coatings for house decors and automobiles, and anticounterfeiting, for example. ${ }^{5}$ These full colored photonic materials ${ }^{6}$ generally consist of block copolymers, cholesteric liquid crystals, or colloidal crystals and they can be patterned by locally chemically modifying their

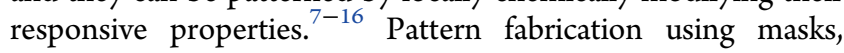
however, severely limits production of diverse patterns, besides yielding patterns with only two colors. Although inkjet printing technology provides a viable solution for creating complex and diverse patterns, achieving full color camouflage in photoniccolored polymers remains a challenge. ${ }^{17,18}$

Cholesteric liquid-crystalline (CLC) or chiral nematic polymers, ${ }^{19-24}$ which are one-dimensional photonic materials, have captivated much attention because of the ease by which they can be fabricated into responsive materials. CLC polymers exhibit selective reflection of only one-handed circularly polarized light due to the presence of helical molecular organization with the wavelength of light reflected being directly proportional to length of the helical pitch. CLC polymers with responsive full color have not been explored. Until now, only chiral nematic mesoporous films with two colors have been reported. ${ }^{17}$ Previously, we have reported an optical calcium sensor based on a CLC polymer showing reflective colors ranging from green to blue. ${ }^{25}$ We now report on a printable blue-colored CLC polymer coating which can be patterned in full colors covering the visible spectrum from $\sim 480$ to $\sim 640 \mathrm{~nm}$ with a single aqueous $\mathrm{Ca}\left(\mathrm{NO}_{3}\right)_{2}$ solution as the ink. The latent pattern reveals itself on exposure to water or by simply exhaling breath onto it (Scheme 1a). Arbitrary full color camouflage patterns can be printed in the photonic polymer which can be, in principle, reprogrammed by acidbase treatment.

\section{EXPERIMENTAL DETAILS}

2.1. Materials. RM257, RM105, and $5 \mathrm{CB}$ were bought from Merck. 6OBA and 6OBAM were obtained from Synthon Chemicals. LC756 was bought from BASF. Irgacure 651 was obtained from CIBA. $\mathrm{KOH}$ pellets and $\mathrm{Ca}\left(\mathrm{NO}_{3}\right)_{2} \cdot 4 \mathrm{H}_{2} \mathrm{O}$ were bought from Sigma-Aldrich. Tetrahydrofuran (THF) was obtained from Biosolve.

2.2. Functionalization of Glass Substrates. Methacrylatefunctionalized and fluorinated alkylsilane-functionalized glass substrates were fabricated as reported previously. ${ }^{25}$ Glass slides were cleaned by sonication (ethanol, $30 \mathrm{~min}$ ) and then treated in a UVozone photoreactor (Ultra Violet Products, PR-100, $20 \mathrm{~min}$ ) to activate the glass surfaces. It was followed by spin coating (3000 rpm, 45 s) 3-(trimethoxysilyl)propyl methacrylate solution (1 vol \% solution in a $1: 1$ water-isopropanol mixture) or $1 \mathrm{H}, 1 \mathrm{H}, 2 \mathrm{H}, 2 \mathrm{H}$ perfluorodecyltriethoxysilane solution ( $1 \mathrm{vol} \%$ solution in ethanol) and then curing $\left(100{ }^{\circ} \mathrm{C}, 10 \mathrm{~min}\right)$ to get methacrylate-functionalized and fluorinated alkylsilane-functionalized glass substrates, respectively.

2.3. Preparation of Responsive CLC Polymer Coating. One gram of CLC mixture consisting of 17.9 wt \% of RM257, 22.9 wt \% of RM105, 18.0 wt \% of each of 6OBA, 6OBAM, and 5CB, 4.6 wt \% of LC756, and 0.6 wt \% of Irgacure 651 was dissolved in $2 \mathrm{~mL}$ of THF. Then $40 \mu \mathrm{L}$ of this solution was cast on a methacrylate-functionalized $3 \times 3 \mathrm{~cm}^{2}$ glass substrate. After the solvent was evaporated by heating

Received: November 23, 2017

Accepted: January 9, 2018

Published: January 9, 2018 
Scheme 1. (a) Schematic of the Working Principle of the Full Color Camouflage in the CLC Polymer Coating; ${ }^{a}$ (b) Structure of the Chemical Components Used To Make the CLC Polymer Coating

(a)

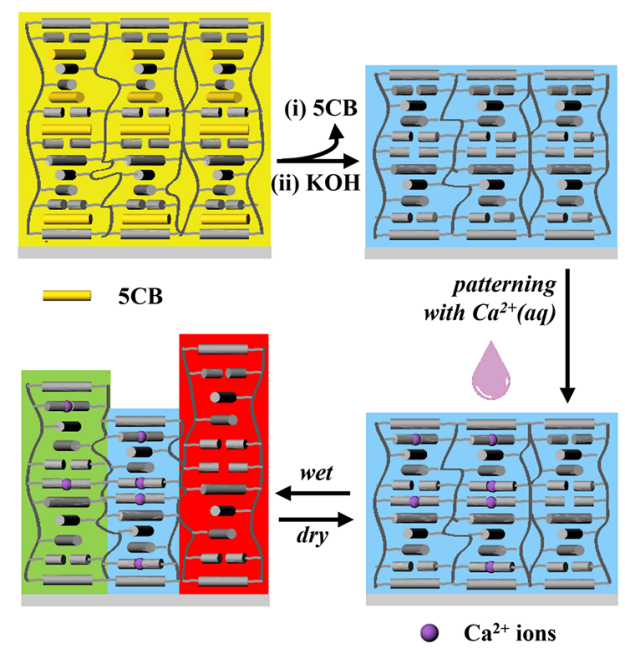

(b)

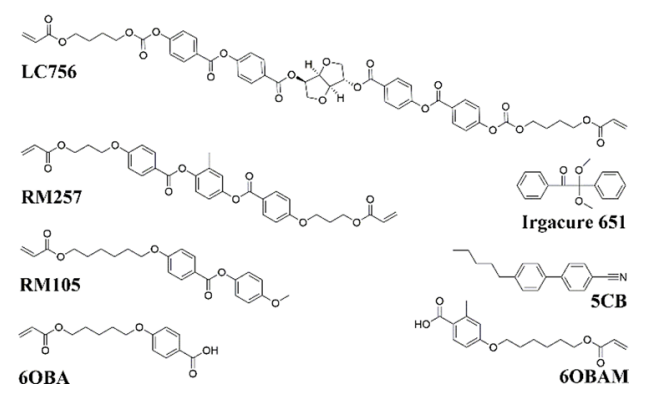

${ }^{a}$ First, the nonreactive mesogen $5 \mathrm{CB}$ was removed, leading to pitch shrinkage. After potassium salt polymer coating was obtained by treating with $\mathrm{KOH}$, an aqueous solution of $\mathrm{Ca}^{2+}$ ions was used for patterning. In the wet state, areas with different amounts of $\mathrm{Ca}^{2+}$ ions swelled differently, giving rise to a full color pattern while staying indistinguishable from each other in a dry blue-colored state.

at $75{ }^{\circ} \mathrm{C}$, a fluorinated alkylsilane-coated $3 \times 3 \mathrm{~cm}^{2}$ glass substrate was placed directly on top and cooled to room temperature with simultaneous shearing along one direction to obtain a greenish yellow film. It was then followed by photopolymerization by shining UV light (48 $\mathrm{mW} \mathrm{cm}^{-2}$ intensity in the range $320-390 \mathrm{~nm}$ ) for $5 \mathrm{~min}$ after which the upper glass plate was removed to obtain the polymer coating. The polymer was first washed in THF and then treated with 1 $\mathrm{M} \mathrm{KOH}$ to obtain the responsive potassium salt CLC polymer coating.

2.4. Characterization. Photopolymerization was done with an Omnicure series 2000 EXFO lamp. UV-visible spectra of the CLC polymer films were recorded in a PerkinElmer lambda 650 spectrophotometer. Ocean Optics UV-visible spectrophotometer HR2000+ mounted on a DM6000 M microscope from Leica Microsystems was used for measuring the transmission spectra of the photonic patterns. Height profile was determined with a Veeco Dektak 150 surface profiler. FT-IR spectra were measured on a Varian 670 FT-IR spectrometer with slide-on ATR (Ge). Inkjet printing was carried out on a Dimatix DMP 2800 (Dimatix-Fijifilm Inc., Santa Clara, USA) equipped with $10 \mathrm{pL}$ cartridge (DMC-11610). Images and movie of the film were captured with a Sony Cyber-shot camera.

2.5. Patterning with Sponge in Polymer Coating. Features of dimension $10 \times 2 \times 1 \mathrm{~mm}^{3}$ were cut out from a kitchen sponge and were soaked each in different concentrations of $\mathrm{Ca}\left(\mathrm{NO}_{3}\right)_{2}$ solution, viz. $0.01,0.1,1,5,10$, and $100 \mathrm{mM}$. The fully soaked sponges were then placed carefully on top of a potassium salt CLC polymer coating. After an hour, the sponges were removed. Some $\mathrm{Ca}\left(\mathrm{NO}_{3}\right)_{2}$ solution droplets which were left behind on the surface of the film were absorbed with dry tissue paper and then washed with running distilled water. A clean glass plate was placed on top to trap the water and keep the coating in wet condition for UV-vis measurements.

2.6. Patterning by Inkjet Printing in Polymer Coating. A 10 $\mathrm{pL}$ cartridge consisting of 12 nozzles with diameter $21.5 \mu \mathrm{m}$ was used for printing. A $100 \mathrm{mM} \mathrm{Ca}\left(\mathrm{NO}_{3}\right)_{2}$ solution was used as the ink. Printing was carried out by using only 6 nozzles at room temperature with a voltage of $14.0 \mathrm{~V}$ and frequency $2.0 \mathrm{kHz}$ using standard waveform. After the printing was over and a waiting period of an hour, the salts that had formed on the surface of the film were removed carefully with tissue paper and then washed with running distilled water. A clean glass plate was placed on top to trap the water and keep the coating in wet condition for UV-vis measurements.

\section{RESULTS AND DISCUSSION}

3.1. Fabrication of CLC Polymer Coating. The printable CLC polymer coating was fabricated from a monomer mixture (Scheme 1b) consisting of diacrylate (RM257) and monoacrylate (RM105) mesogens. Hydrogen-bonded benzoic acidfunctionalized polymerizable reactive mesogens (6OBA and 6OBAM) were used as ligands to bind to calcium ions. To induce a CLC phase, a right-handed chiral dopant (LC756), ${ }^{26}$ which also acts as a cross-linker, was added. Lastly, to enhance the response of the polymer coating to obtain a wide range of structural colors from blue to red, a removable, nonreactive mesogen (5CB) was used. The mixture also contained a photoinitiator (Irgacure 651, $0.6 \mathrm{wt} \%$ ) to initiate the photopolymerization reaction. Shearing the CLC monomer mixture between methacrylate-functionalized and fluorinated alkylsilane-functionalized substrates resulted in planar alignment of the molecules which was frozen by photopolymerization using UV light. Removal of the top glass plate followed by washing away of the nonreactive mesogen $5 \mathrm{CB}$ with THF revealed a blue-colored CLC polymer coating $(\lambda=450 \mathrm{~nm})$ covalently bonded to the bottom plate (Figure $\mathrm{S} 1 \mathrm{a}-\mathrm{c}$ ). ${ }^{25}$ Treating the film with $\mathrm{KOH}$ solution resulted in rupture of hydrogen bonds and formation of potassium salt polymer. On drying, a $15 \mu \mathrm{m}$ thick (Figure S1d) blue reflective $(\lambda=450 \mathrm{~nm})$ hygroscopic polymer coating was obtained, which swelled and became red $(\lambda=630 \mathrm{~nm})$ upon exposure to water due to an increase in the helical pitch. Drying led to pitch shrinkage and the coating returned to a blue color $(\lambda=450 \mathrm{~nm})$, demonstrating a reversible color change covering almost the entire visible light spectrum.

3.2. Full Color Pattern Using $\mathrm{Ca}^{2+}$ as Cross-linking Agent. The color of the wet CLC polymer coating can be modified by $\mathrm{Ca}^{2+}$ ions which replaces $\mathrm{K}^{+}$ions and bind to the benzoate moieties. ${ }^{25}$ Hence, photonic patterns can be created by locally introducing $\mathrm{Ca}^{2+}$ ions as cross-linkers. To determine the appropriate concentration of $\mathrm{Ca}\left(\mathrm{NO}_{3}\right)_{2}$ solutions required to achieve different colors in the visible spectrum, sponges were used in the form of stamps. ${ }^{27}$ Sponges of $10 \times 2 \times 1 \mathrm{~mm}^{3}$ were simply cut out from a kitchen sponge and soaked in different concentrations of $\mathrm{Ca}\left(\mathrm{NO}_{3}\right)_{2}$ solution ranging from 0.01 to 100 $\mathrm{mM}$. The sponges were then placed carefully on top of the potassium salt photonic coating. A color change took place in less than a minute, indicating a rapid $\mathrm{K}^{+} / \mathrm{Ca}^{2+}$ ion exchange. $\mathrm{UV}$-vis spectroscopy of the wet polymer coating showed only one reflection band for any concentration employed, suggesting that $\mathrm{K}^{+}$and $\mathrm{Ca}^{2+}$ ions are uniformly distributed throughout the thickness of the film (Figure 1a). With concentrations 0.01 and 


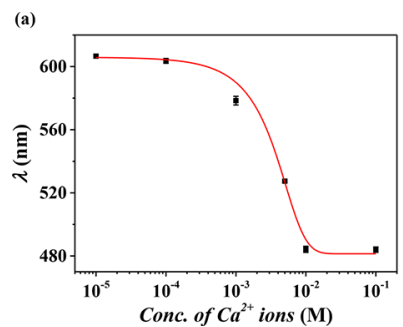

(b)
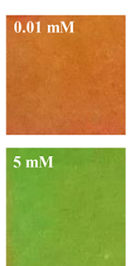

Conc. of $\mathrm{Ca}^{2+}$ ions (M)

Figure 1. (a) Wavelength of light reflected by CLC potassium salt polymer coating treated with different concentrations of $\mathrm{Ca}\left(\mathrm{NO}_{3}\right)_{2}$ solution. The red line represents the fitted curve. Error bars indicate mean \pm standard deviations for five measurements at different places on the pattern. (b) Images of the CLC coatings patterned with kitchen sponges soaked in different concentrations of $\mathrm{Ca}\left(\mathrm{NO}_{3}\right)_{2}$ solution.

$0.1 \mathrm{mM}$, the coating was found to reflect around $605 \mathrm{~nm}$, that is, $\Delta \lambda \approx 33 \mathrm{~nm}$ blue-shifted with respect to wet potassium salt coating, resulting in an orange color (Figure 1b). With increasing concentration, the wavelength of light reflected blue-shifted further due to a lower degree of swelling, causing a decrease in pitch length. A concentration of $1 \mathrm{mM}$ gave rise to yellow color $(\lambda \approx 578 \mathrm{~nm} ; \Delta \lambda \approx 60 \mathrm{~nm})$ and $5 \mathrm{mM}$ resulted in a green reflection band $(\lambda \approx 527 \mathrm{~nm} ; \Delta \lambda \approx 81 \mathrm{~nm})$. With higher concentration of $10 \mathrm{mM}$, the film became blue $(\lambda \approx 484$ $\mathrm{nm} ; \Delta \lambda \approx 124 \mathrm{~nm})$. Increasing the concentration to $100 \mathrm{mM}$ did not cause any further color shift and the film remained blue, suggesting all the $\mathrm{K}^{+}$ions have been replaced by $\mathrm{Ca}^{2+}$ ions, leading to a fully cross-linked polymer network with drastically reduced degree of swelling. This data showed that the color of the photonic polymer can be changed from red to blue $(\sim 480$ to $\sim 640 \mathrm{~nm}$ ) by varying the calcium concentration between 0.1 and $10 \mathrm{mM}$.

The use of sponge as a stamp to write full color patterns was first investigated. The logo of the Eindhoven University of Technology "TU/e", which have the letters "T", "U", and "e" in blue and the slash "/" in red was chosen as the full color pattern. The background was selected to be green, and therefore a sponge $(1 \mathrm{~mm}$ thick) soaked in $1 \mathrm{mM}$ concentration of $\mathrm{Ca}\left(\mathrm{NO}_{3}\right)_{2}$ was used as a stamp to generate the green background. A small area was left untreated so that it would develop into a red slash upon swelling with water. The background consisted of both $\mathrm{Ca}^{2+}$ and $\mathrm{K}^{+}$ions homogeneously distributed while the slash consisted of $\mathrm{K}^{+}$ions only. Creating the letters with sponges of the same thickness $(1 \mathrm{~mm})$ soaked in $100 \mathrm{mM}$ concentration of $\mathrm{Ca}\left(\mathrm{NO}_{3}\right)_{2}$ then led to local exchange of the remaining $\mathrm{K}^{+}$ions with $\mathrm{Ca}^{2+}$. Wetting the patterned blue coating with water revealed the full color "TU/ $\mathrm{e}$ " image (Figure 2a). As designed, the background was green $(\lambda \approx 570 \mathrm{~nm})$ and letters were blue $(\lambda \approx 483 \mathrm{~nm})$ while the slash was red $(\lambda \approx 636 \mathrm{~nm})$ (Figure $2 \mathrm{~b}$ ). Height profile measurement of the wet coating revealed a decrease in thickness in the region where the letters were written by 3.1 $\mu \mathrm{m}$ which translates to a $16.1 \%$ reduction (Figure $2 \mathrm{c}$ ). This

(a)
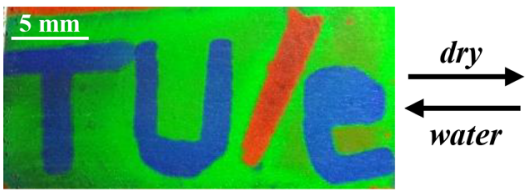

(c)
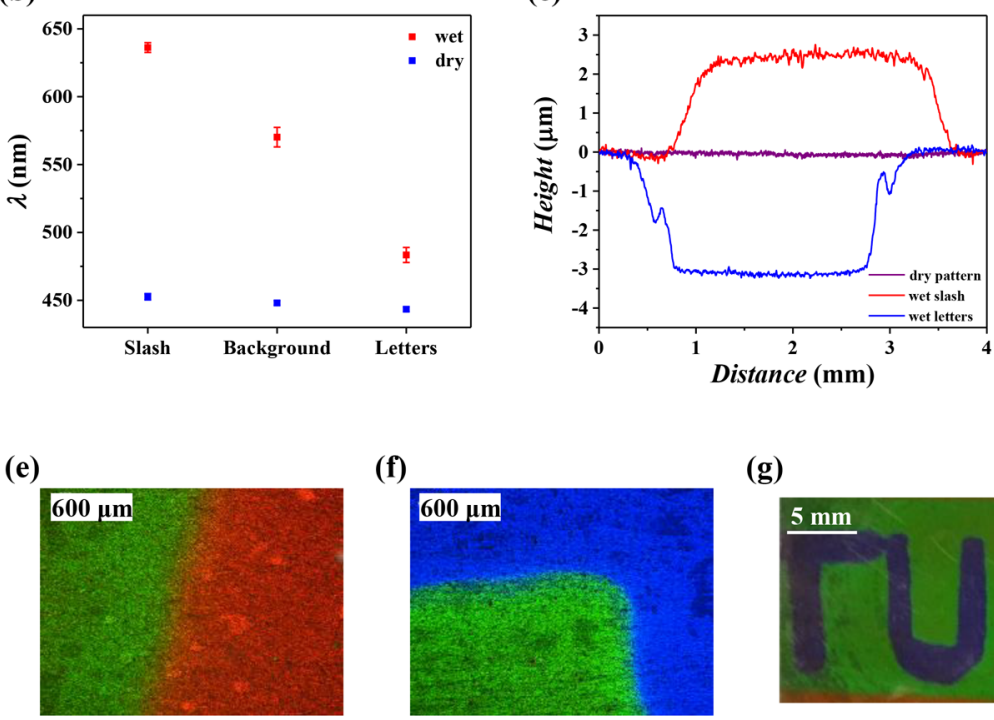

(f)

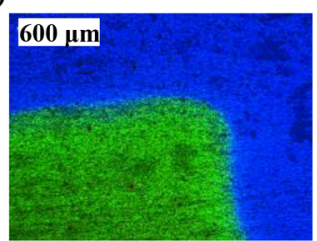

(g)

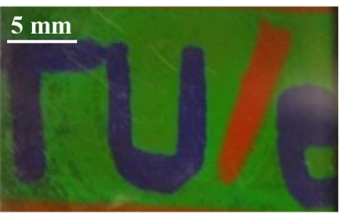

(d)

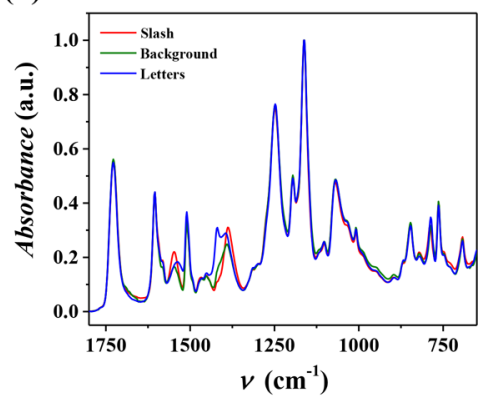

(h)

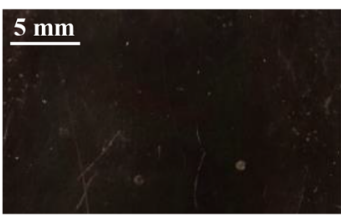

Figure 2. (a) Image of a sponge-written "TU/e" logo that appeared in wet state on exposure to water or exhaled breath but remained hidden in the dry state. (b) Wavelength of light reflected by the "TU/e" logo in wet and dry state. Error bar indicates mean \pm standard deviations for five measurements at different places on the pattern. (c) Height profile of the "TU/e" logo in wet state showed swelling for the slash and shrinkage for the letters with respect to the green background and nearly flat surface in the dry state. (d) FT-IR spectra of the patterned CLC polymer coating. Slash consisted of only $\mathrm{K}^{+}$ions. Background consisted of both $\mathrm{K}^{+}$and $\mathrm{Ca}^{2+}$ ions. Letters consisted of only $\mathrm{Ca}^{2+}$ ions. Polarized optical microscopy image (in incidence light mode) of (e) slash and (f) letter "T". Image of the "TU/e" pattern on wet coating as seen through (g) right-handed and (h) left-handed circular polarizer. 
corresponds well with the observed $15.3 \%$ decrease in the pitch length. On the other hand, the thickness increased by $2.3 \mu \mathrm{m}$ in the region where the slash was written. This amounts to a $13 \%$ increase, corresponding fairly well with the observed $11.6 \%$ increase in pitch length on swelling. Polarized optical microscopy (POM) images showed a sharp border of the patterned area (Figure 2e,f), implying ions did not undergo lateral diffusion into the nonpatterned area, probably due to the anisotropy of the CLC material. The FT-IR spectra showed shifting of symmetric stretching peak of benzoate salt to higher frequency, from 1387 to $1394 \mathrm{~cm}^{-1}$, while the asymmetric stretching peak shifted to lower frequency, from 1547 to 1537 $\mathrm{cm}^{-1}$, confirming the formation of calcium benzoate dimers (Figure 2d) in the letter patterned areas. ${ }^{25,28,29}$ Drying the film resulted in disappearance of the pattern and the coating was totally blue $(\lambda \approx 448 \mathrm{~nm})$ with a nearly flat surface profile (Figure 2b,c).

The trigger to reveal the hidden pattern is not limited to water. Water vapor present in exhaled breath (relative humidity $\approx 95 \%$ ) was also enough to swell the coating to the same extent as that of water (Figure 2a). Response of the patterned coating was studied for ten cycles of exhaling breath (Figure S2a). It was found that repeated exposure to breath had negligible effect on the optical response of the coating. After the first cycle, the red slash became more orange but in the later cycles, the reflection wavelength stayed nearly the same (Figure S2b). After the tenth cycle of exposure to exhaled breath, the color of the green background and blue letters remained nearly unchanged, implying that the response of the coating to breath is fully reversible. It should be noted that the colored photonic patterns can also be hidden using a circular polarizer. The pattern in the right-handed CLC polymer coating was visible through a right-handed circular polarizer while through a lefthanded circular polarizer it was invisible and appeared completely dark (Figure 2g,h).

3.3. Arbitrary Full Color Patterning by Inkjet Printing. To demonstrate that arbitrary full color high-resolution patterns could be easily fabricated in the photonic polymer coatings, inkjet printing was explored with $100 \mathrm{mM} \mathrm{Ca}\left(\mathrm{NO}_{3}\right)_{2}$ aqueous solution as a single ink. With a cartridge that ejects drops of $10 \mathrm{pL}$ volume and $27 \mu \mathrm{m}$ diameter, a line pattern of width $1 \mathrm{~mm}$ (Figure S3) was printed with spacing between the drops as $20 \mu \mathrm{m}$ (1270 dpi). Swelling with water resulted in orange color pattern $(\lambda \approx 608 \mathrm{~nm})$, slightly blue-shifted by $\Delta \lambda$ $\approx 28 \mathrm{~nm}$ with respect to the nonprinted red area $(\lambda \approx 636 \mathrm{~nm})$ (Figure S4). Printing a second layer on top of the first layer resulted in an increase in the amount of $\mathrm{Ca}^{2+}$ ions in the polymer network, leading to less swelling, and the pattern became yellowish green $(\lambda \approx 570 \mathrm{~nm} ; \Delta \lambda \approx 66 \mathrm{~nm})$. On printing a third layer, the pattern became green $(\lambda \approx 532 \mathrm{~nm}$; $\Delta \lambda \approx 104 \mathrm{~nm}$ ) upon swelling. Printing additional layers led to further blue shifting of the reflection band until it became nearly constant around $\lambda \approx 489 \mathrm{~nm}$ (blue color; $\Delta \lambda \approx 147 \mathrm{~nm}$ ) for 10 layers and more.

After having determined the number of layers required for obtaining a specific color, a flower with blue petals, green leaf and stem, and red pistils and background was chosen as an image for inkjet printing. With use of the cartridge with 100 $\mathrm{mM} \mathrm{Ca}\left(\mathrm{NO}_{3}\right)_{2}$ ink solution and the same drop spacing of 20 $\mu \mathrm{m}$ (1270 dpi), the flower pattern was printed by varying the number of layers accordingly. The flower pattern stayed hidden in the dry state but in the wet state-either via exhaled breath or treatment with water-appeared in full color with high resolution (Figure 3, Movie S1). The POM images showed that the patterns were of uniform color, implying the drop spacing

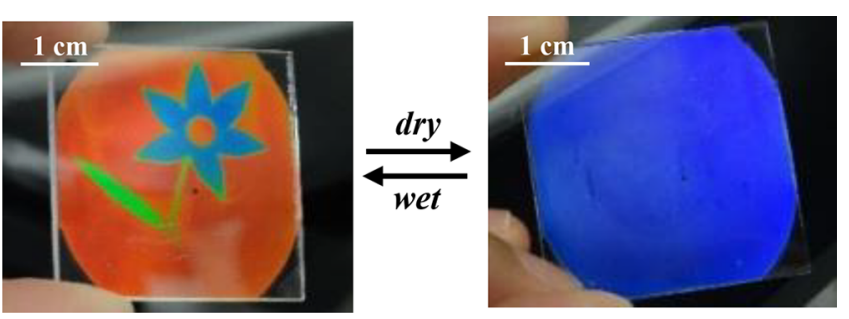

Figure 3. Image of an inkjet-printed full color flower pattern which appeared in the wet state but was hidden in the dry state.

was optimum for obtaining uniform layers of the ink. The border of the pattern was sharp for the green leaf-stem (Figure S5a). However, the blue petals were surrounded by a $\sim 170 \mu \mathrm{m}$ broad green border (Figure S5b). As no lateral ion diffusion was observed in the case of sponge written patterns (vide supra), it is unlikely to occur in the inkjet-printed patterns. A possible explanation could be coalescence of printed ink drops at the border toward the bulk of the pattern causing a gradient of $\mathrm{Ca}^{2+}$ ions. The wavelength difference between the blue petals and the red background is large $(\Delta \lambda \approx 145 \mathrm{~nm})$ while that between the green leaf-stem and the red background is relatively small $(\Delta \lambda \approx 87 \mathrm{~nm})$; as a result, the gradient in $\mathrm{Ca}^{2+}$ concentration causing a gradient in color is more pronounced in the blue petals. Interestingly, the printed patterns could be erased by reprotonating the benzoate moieties by treating with an acid such as $\mathrm{HNO}_{3}$ (Figure S6) revealing the possibility to erase and reprogram the camouflage patterns. ${ }^{25}$

For the making of green, yellow, and orange colors with more precise wavelengths, a different concentration of calcium nitrate could be used. For example, with use of a lower concentration $10 \mathrm{mM} \mathrm{Ca}\left(\mathrm{NO}_{3}\right)_{2}$ solution as the ink, patterns that reflect light of wavelength between 608 and $570 \mathrm{~nm}$ and 570 and $532 \mathrm{~nm}$ could also be obtained (Figure S4), signifying the versatility of $\mathrm{Ca}\left(\mathrm{NO}_{3}\right)_{2}$ solution in producing full color, covering almost the entire visible spectra from red to blue by simply varying the number of layers of the ink- 100 or $10 \mathrm{mM}$ concentrations. The photonic patterning by inkjet printing can be easily extended to printing any color pattern on any color background. For example, the "TU/e" logo could be printed with a green background and red slash and blue letters (Figure S7) to obtain a high-resolution pattern with sharp borders in the wet state.

\section{CONCLUSIONS}

We have fabricated a printable blue-colored CLC polymer coating that could be patterned with a single ink-calcium nitrate solution, in full colors covering the visible spectra from blue to red $(\sim 480$ to $\sim 640 \mathrm{~nm})$. The patterns on the polymer functioned similarly to the naturally observed camouflage behavior by remaining hidden in dry environment and revealing itself in the presence of water or exhaled breath. The range of colors achievable could be tuned by simply changing the composition of the nonreactive mesogen. The responsive full color patterned photonic polymers open up many interesting applications of photonic materials in the direction of adaptive camouflage textiles, anticounterfeit labels, data encryptions as well as for aesthetic purposes including home decorations and automobile coatings. 


\section{ASSOCIATED CONTENT}

\section{S Supporting Information}

The Supporting Information is available free of charge on the ACS Publications website at DOI: 10.1021/acsami.7b17892.

Photographs of polymer coatings, optical microscopy images of photonic patterns, height profile, and FT-IR and UV-vis measurements (PDF)

Movie of inkjet-printed full color camouflage polymer (MPG)

\section{AUTHOR INFORMATION}

\section{Corresponding Author}

*E-mail: a.p.h.j.schenning@tue.nl (A.P.H.J.S.).

\section{ORCID $\odot$}

Albertus P. H. J. Schenning: 0000-0002-3485-1984

\section{Author Contributions}

The manuscript was written through contributions of all authors. All authors have given approval to the final version of the manuscript.

\section{Notes}

The authors declare no competing financial interest.

\section{ACKNOWLEDGMENTS}

The research was made possible by a grant of The Netherlands Foundation for Scientific Research (NWO) for bilateral research program between The Netherlands and India on "Functional Materials". The authors thank Anouk F. Scheers for her initial work on inkjet printing on polymer coating. The authors also thank Michael G. Debije for his valuable comments on the manuscript.

\section{REFERENCES}

(1) Sun, J.; Bhushan, B.; Tong, J. Structural Coloration in Nature. RSC Adv. 2013, 3 (35), 14862-14889.

(2) Kreit, E.; Mathger, L. M.; Hanlon, R. T.; Dennis, P. B.; Naik, R. R.; Forsythe, E.; Heikenfeld, J. Biological versus Electronic Adaptive Coloration: How Can One Inform the Other? J. R. Soc., Interface 2013, 10 (78), 20120601.

(3) Mathger, L. M.; Denton, E. J.; Marshall, N. J.; Hanlon, R. T. Mechanisms and Behavioural Functions of Structural Coloration in Cephalopods. J. R. Soc., Interface 2009, 6 (Suppl_2), S149-S163.

(4) Teyssier, J.; Saenko, S. V.; van der Marel, D.; Milinkovitch, M. C. Photonic Crystals Cause Active Colour Change in Chameleons. Nat. Commun. 2015, 6, 6368.

(5) Phan, L.; Walkup, W. G., IV; Ordinario, D. D.; Karshalev, E.; Jocson, J. M.; Burke, A. M.; Gorodetsky, A. A. Reconfigurable Infrared Camouflage Coatings from a Cephalopod Protein. Adv. Mater. 2013, 25 (39), 5621-5625.

(6) Ge, J.; Yin, Y. Responsive Photonic Crystals. Angew. Chem., Int. Ed. 2011, 50 (7), 1492-1522.

(7) Xuan, R; Ge, J. Invisible Photonic Prints Shown by Water. J. Mater. Chem. 2012, 22 (2), 367-372.

(8) Wang, Z.; Zhang, J.; Xie, J.; Wang, Z.; Yin, Y.; Li, J.; Li, Y.; Liang, S.; Zhang, L.; Cui, L.; Zhang, H.; Yang, B. Polymer Bragg Stack as Color Tunable Photonic Paper. J. Mater. Chem. 2012, 22 (16), 78877893.

(9) Ye, S.; Fu, Q.; Ge, J. Invisible Photonic Prints Shown by Deformation. Adv. Funct. Mater. 2014, 24 (41), 6430-6438.

(10) Li, Q.; Qi, N.; Peng, Y.; Zhang, Y.; Shi, L.; Zhang, X.; Lai, Y.; Wei, K.; Kim, I. S.; Zhang, K.-Q. Sub-Micron Silk Fibroin Film with High Humidity Sensibility through Color Changing. RSC Adv. 2017, 7 (29), 17889-17897.
(11) Ye, S.; Ge, J. Soaking Based Invisible Photonic Print with a Fast Response and High Resolution. J. Mater. Chem. C 2015, 3 (3), 80978103.

(12) Chen, M.; Tian, Y.; Zhang, J.; Hong, R; Chen, L.; Chen, S.; Son, D. Y. Fabrication of Crack-Free Photonic Crystal Films via Coordination of Microsphere Terminated Dendrimers and Their Performance in Invisible Patterned Photonic Displays. J. Mater. Chem. C 2016, 4 (37), 8765-8771.

(13) Hu, H.; Zhong, H.; Chen, C.; Chen, Q. Magnetically Responsive Photonic Watermarks on Banknotes. J. Mater. Chem. C 2014, 2 (19), 3695-3702.

(14) Hu, H.; Tang, J.; Zhong, H.; Xi, Z.; Chen, C.; Chen, Q. Invisible Photonic Printing: Computer Designing Graphics, UV Printing and Shown by a Magnetic Field. Sci. Rep. 2013, 3 (1), 1484.

(15) Fang, Y.; Leo, S. Y.; Ni, Y.; Wang, J.; Wang, B.; Yu, L.; Dong, Z.; Dai, Y.; Basile, V.; Taylor, C.; Jiang, P. Reconfigurable Photonic Crystals Enabled by Multistimuli-Responsive Shape Memory Polymers Possessing Room Temperature Shape Processability. ACS Appl. Mater. Interfaces 2017, 9 (6), 5457-5467.

(16) Fang, Y.; Ni, Y.; Leo, S.-Y.; Wang, B.; Basile, V.; Taylor, C.; Jiang, P. Direct Writing of Three-Dimensional Macroporous Photonic Crystals on Pressure-Responsive Shape Memory Polymers. ACS Appl. Mater. Interfaces 2015, 7 (42), 23650-23659.

(17) Khan, M. K.; Bsoul, A.; Walus, K.; Hamad, W. Y.; Maclachlan, M. J. Photonic Patterns Printed in Chiral Nematic Mesoporous Resins. Angew. Chem., Int. Ed. 2015, 54 (14), 4304-4308.

(18) Kang, H. S.; Lee, J.; Cho, S. M.; Park, T. H.; Kim, M. J.; Park, C.; Lee, S. W.; Kim, K. L.; Ryu, D. Y.; Huh, J.; Thomas, E. L.; Park, C. Printable and Rewritable Full Block Copolymer Structural Color. Adv. Mater. 2017, 29 (29), 1-8.

(19) Moirangthem, M.; Schenning, A. P. H. J. Cholesteric Liquid Crystalline Polymer Networks as Optical Sensors. In Liquid Crystal Sensors; Schenning, A. P. H. J., Crawford, G. P., Broer, D. J., Eds.; Taylor \& Francis Group: Boca Raton, FL, 2017; pp 83-102.

(20) Mulder, D.-J.; Schenning, A. P.H.J.; Bastiaansen, C. W.M. Chiral-Nematic Liquid Crystals as One Dimensional Photonic Materials in Optical Sensors. J. Mater. Chem. C 2014, 2 (33), 66956705.

(21) White, T. J.; McConney, M. E.; Bunning, T. J. Dynamic Color in Stimuli-Responsive Cholesteric Liquid Crystals. J. Mater. Chem. 2010 20 (44), 9832-9847.

(22) Li, Q. Intelligent Stimuli Responsive Materials: From Well-Defined Nanostructures to Applications; John Wiley \& Sons: Hoboken, NJ, 2013.

(23) Lu, J.; Gu, W.; Wei, J.; Zhang, W.; Zhang, Z.; Yu, Y.; Zhou, N.; Zhu, X. Novel Planar Chiral Dopants with High Helical Twisting Power and Structure-Dependent Functions. J. Mater. Chem. C 2016, 4 (40), 9576-9580.

(24) Li, Q.; Li, Y.; Ma, J.; Yang, D. K.; White, T. J.; Bunning, T. J. Directing Dynamic Control of Red, Green, and Blue Reflection Enabled by a Light-Driven Self-Organized Helical Superstructure. $A d v$. Mater. 2011, 23 (43), 5069-5073.

(25) Moirangthem, M.; Arts, R.; Merkx, M.; Schenning, A. P. H. J. An Optical Sensor Based on a Photonic Polymer Film to Detect Calcium in Serum. Adv. Funct. Mater. 2016, 26 (8), 1154-1160.

(26) Galagan, Y.; Debije, M. G.; Blom, P. W. M. Semitransparent Organic Solar Cells with Organic Wavelength Dependent Reflectors. Appl. Phys. Lett. 2011, 98 (4), 043302.

(27) De Haan, L. T.; Verjans, J. M. N.; Broer, D. J.; Bastiaansen, C. W. M.; Schenning, A. P. H. J. Humidity-Responsive Liquid Crystalline Polymer Actuators with an Asymmetry in the Molecular Trigger That Bend, Fold, and Curl. J. Am. Chem. Soc. 2014, 136 (30), 10585-10588.

(28) Dudev, T.; Lim, C. The Effect of Metal Binding on the Characteristic Infrared Band Intensities of Ligands of Biological Interest. J. Mol. Struct. 2012, 1009, 83-88.

(29) Spinner, E. Vibration-Spectral Studies of Carboxylate Ions. Part 11.l Substituted Benzoate Ions. J. Chem. Soc. B 1967, 6 (874), 874879. 